\title{
The Development of a Methodology for Calibrating a Large-Scale Laboratory Rainfall Simulator
}

\author{
Haksoo Kim $『$, Teakjo Ko *, Hyangseon Jeong and Sungje Ye \\ National Disaster Management Research Institute, Ulsan 44538, Korea; hskim73@korea.kr (H.K); \\ jhs99@korea.kr (H.J.); hiseesu12@korea.kr (S.Y.) \\ * Correspondence: kotjo0329@korea.kr; Tel.: +82-52-928-8450
}

Received: 20 September 2018; Accepted: 31 October 2018; Published: 2 November 2018

check for updates

\begin{abstract}
The objective of this study was to establish a method to calibrate a large-scale laboratory rainfall simulator through developing and implementing an automated rainfall collection system to assess the reliability and accuracy of a rainfall simulator. The automated rainfall collection system was designed to overcome the limitations caused by the traditional manual measurement for obtaining the rainfall intensity and the spatial rainfall distribution in a large experimental area. The developed automated rainfall collection system was implemented to calibrate a large-scale laboratory rainfall simulator. The adequacy of average rainfall intensities automatically collected from the miniature tipping bucket rain gauges was assessed by comparison with those based on the volumetric method using the flowmeter. The functional relationships between the system variables of the rainfall simulator and the simulated intensity and uniformity distribution of rainfall (i.e., operation models) were derived based on a multiple regression approach incorporating correlation analysis on linear and logarithm scales, with consideration of a significance level. The operation models exhibited high accuracy with respect to both the rainfall intensity and the uniformity coefficients.
\end{abstract}

Keywords: automated rainfall collection system; large-scale laboratory rainfall simulator; rainfall intensity; spatial rainfall distribution; operation model

\section{Introduction}

Rainfall-runoff is an important hydrological process that affects many different types of environmental factors including soil, topography, vegetation, and natural resources within catchments. Runoff studies are often dependent on the characteristics of natural rainfall such as its variability in intensity, spatio-temporal distribution, drop size distribution, drop velocity, and kinetic energy [1]. Rainfall simulation is the prevalent method applied in hydrogeomorphological studies that include runoff, infiltration, soil characteristics in catchments, and other study areas for replicating the features and processes of natural rainfall [2].

A rainfall simulator (RS) is widely used as research tool to produce runoff, infiltration, and erosion data in field- and laboratory-based studies of hydrological and geomorphological processes [3-6]. The main purpose of an RS is to provide a reproducible collection of rainfall data as well as to accurately and precisely create a variety of rainfall regimes by controlling the rainfall intensity and duration $[2,7,8]$. The data collected from rainfall simulation experiments provide fundamental information to understand the dynamic behaviors of runoff generation, infiltration and soil erosion; this information is focused on how surface properties such as slope, soil properties, vegetation cover, and topography within catchments impact the above-mentioned processes $[9,10]$.

There is no universal RS applicable to all study conditions [5,9]. Many different types of RSs have been developed to study various components of hydrological and geomorphological processes through the artificial reproduction of rainfall $[5,11,12]$. RSs can be classified into two main groups 
according to the method through which the drop-forming mechanism creates rain $[3,6,8,11]$. The first group consists of the non-pressurized drop-forming simulators, where the raindrops are formed at the tip of a conduit (i.e., drop former), such as needles connected to a set of pipes, or directly from holes in the base of a tank. The drop formers initiate the fall of drops with zero velocity. The second group consists of pressurized nozzle simulators, where the raindrops are continuously produced by single or multiple nozzles at significant velocities.

Non-pressurized drop-forming simulators have limitations in reproducing natural rainfall in terms of drop size and energy characteristics $[2,8,11,13]$. These types of simulators generally provide uniformly distributed raindrops in terms of size; however, they do not produce a distribution of drops unless various sizes or dimensions of drop formers are used. Another shortcoming of the non-pressurized drop-forming simulators is the limited application to soil erosion studies, particularly in field experiments. These simulators are usually impractical for field use because a sufficient height from the impact surface is needed for raindrops to reach terminal velocity corresponding with rainfall kinetic energy.

By contrast, the pressurized nozzle simulators produce wider drop-size distributions. A variety of nozzle types can be employed in rainfall simulation, and drop-size distributions are governed by the shape features and discharge of the nozzle. These types of simulators also provide a variety of storm intensities $[13,14]$. Rainfall intensities can be varied with nozzle orifice, pump pressure, nozzle spacing, and nozzle movements. While these simulators provide reasonable velocities and kinetic energy values of raindrops at low fall heights, droplet velocities are generally exaggerated because the raindrops from nozzles have an initial velocity greater than zero due to the pump pressure forcing them out. The continuous spray from the nozzles may also lead to higher rainfall intensities than natural rainfall. A rotating disc, a rotating boom, an oscillating bar, or a solenoid-controlled simulator can be used as the solution to reduce the exaggerated rainfall intensity $[2,8,15]$. A rotating or oscillating bar is the simplest method of closely simulating natural rainfall in terms of rainfall intensities [16]. Boxes around nozzles to regulate sprayed raindrops are also introduced to decrease rainfall intensity higher than that of natural rainfall by reducing the time of surface exposure to the artificial rain spray [8].

There are also indoor and outdoor RSs according to transportability [7]. Small, portable field RSs can be useful due to their easy and rapid transport and implementation, but the small size generally limits their applications to accurate assessment of the net runoff response, including heterogeneity in surface properties at the plot scale [10]. On the other hand, laboratory RSs have been used to overcome the disadvantages of the small, portable field RSs [2,7]. Laboratory RSs prevent the disruptive impacts of wind, temperature, and humidity on experiments [17].

Recently, research has focused more on the assessment of the effects of surface property changes resulting from fire, agriculture, urbanization or other disturbances on the hydrologic cycle [18-24]. These studies include broad experiments that evaluate the characteristics of the land surface on a scale from a hillslope to a catchment to further understand the interplay between surface properties and runoff generation. This requires a laboratory RS that is sufficiently large to produce high rainfall intensities and that is suited to capture heterogeneity of surface properties across an experimental surface. Such measurements from a large laboratory RS can be used to increase the runoff response accuracy and precision of hydrological models [10]. Although additional research using large laboratory RSs is needed to assess the effects of surface property changes on the hydrologic cycle, simple and small RSs that produce rain over small areas (less than $5 \mathrm{~m}^{2}$ and mostly less than $1 \mathrm{~m}^{2}$ ) have been widely used [5,12,25-32]. This is due to the fact that RSs covering relatively large areas (approximately $100 \mathrm{~m}^{2}$ or more) are expensive to set up and are not easy to operate [2].

For accurate runoff experiments, the RSs should adequately simulate natural rainfall and control the intensity and duration of the rainfall. In addition to the desirable characteristics for precisely simulating rainfall, RSs need other requirements such as efficiency, simplicity, and economy [33]. However, it is difficult to meet the all requirements for RSs because there is a trade-off among the desirable characteristics such as size, cost, portability, areal coverage, ease of use, 
and operation $[10,11,34]$. The desirable features of RSs primarily depend on the research objectives and the rainfall characteristics required for specific research conditions.

In the case of large indoor RSs, major requirements for runoff experiments include reliability and accuracy. Reliability is associated with the repeatability of storm events, and accuracy relates to spatial uniformity in rainfall over the entire test plot [8]. A reproducible rainfall pattern can be provided more reliably when the desired intensities and duration of the storm are controlled by the computer-driven operation system. This removes the problems related to human errors in changing the storm pattern. The reliability can also be enhanced by implementing appropriate instrumentation that correctly monitors storm events across the test plot. Accuracy is evaluated by the degree of uniformity of rainfall distribution over the test plot. The accuracy can be increased or at least be as high as possible when an adequate spray nozzle type is chosen and nozzles are placed in series with adequate spacing to ensure even overlap of raindrops. Additionally, the physical movement of the nozzles back and forth across an experimental plot can have notable effects on the uniformity of rainfall distribution [8].

In general, the depths and spatial distribution of rainfall are manually measured with collection containers equally distributed over an entire experimental plot to provide quantitative information on the reproducibility and homogeneity of rainfall. The mass of water collected in each container during an experiment is converted to rainfall depth per hour, and then the mean simulated rainfall intensities are calculated. The spatial homogeneity of a certain rainfall event is mostly evaluated using the Christiansen uniformity coefficient (CuC) [35]. This type of experiment is repeated for different rainfall intensities and for different runs at the same intensity.

These traditional measurements are widely used for small-scale rainfall simulation, while manual procedures are not suitable for relatively large experimental areas $\left(100 \mathrm{~m}^{2}\right.$ or more) because of the inefficiency in terms of the time and human resources required to cover large areas. The intensity and spatial distribution of rainfall are controlled by a combination of the variables of an RS system, such as the orifice diameter of the nozzle, the pressure at the nozzle and the nozzle movement (e.g., the oscillation speed of bars and the time delay at the end of each oscillation). The larger the RS, the more system variables the RS has, and hence the more difficult it is to fit the target intensity for a specified time period having a reasonable uniformity of rainfall distribution because of the increased number of combinations in the RS's system variables. In addition, traditional measurement based on manual procedures has its own sources of errors due to human mistakes. These measurement errors vary randomly in magnitude under the same conditions of the RS's system variables. If errors in rainfall intensity generated from an RS are not considered before use in analysis, the researchers could draw erroneous conclusions regarding the study objective, such as infiltration, pavement effects in urbanized areas, and storage capacity of catchments [36].

In addition, a variety of rainfall simulators have been calibrated over an experimental area, often with little consideration of issues such as interrelationships of the system variables of the RS and the intensity and uniformity distribution of rainfall. In particular, in a large RS, limited attention is placed on the identification of relationships between the system variables of the RS and the intensity and uniformity distribution of rainfall, even though those relationships are very important to produce and replicate a steady supply of rainfall at a fixed and known intensity, and there are also increasing issues related to the use of a large RS in hydrogeomorphological studies. To overcome the limitations caused by manual measurements to obtain the rainfall intensity and spatial rainfall distribution in a large experimental area, an additional device is required. The main purpose of this study is to establish a method to calibrate a large-scale laboratory rainfall simulator through developing and implementing an automated rainfall collection system (ARCS) to assess the reliability and accuracy of a rainfall simulator. The ARCS is implemented to identify functional relationships between the system variables of the RS and the intensity and uniformity distribution of rainfall (i.e., operation models). The operation models can be used as a guideline to intuitively select appropriate ranges of the system variables of the rainfall simulator to generate a particular rainfall intensity and degree of uniformity for simulated rainfall in laboratory-based studies of hydrological and geomorphological processes. 


\section{Large-Scale Laboratory Rainfall Simulator}

The large-scale laboratory RS of the NDMI (National Disaster Management Research Institute) reproduces spatially uniform rainfall with an oscillating nozzle system for experimental areas up to $900 \mathrm{~m}^{2}$. The RS is a pressurized nozzle-type simulator with computer-operated oscillating booms. The NDMI RS consists of several parts: an underground water storage tank $\left(900 \mathrm{~m}^{3}\right)$, submersible pumps $\left(0.25 \mathrm{~m}^{3} / \mathrm{s} \times 4\right.$ pumps), a rooftop water storage tank $\left(63 \mathrm{~m}^{3}\right)$, a water supply system (from submersible pumps to nozzles), booster pumps $\left(1.7 \mathrm{~m}^{3} / \mathrm{min} \times 3\right.$ pumps), computer-driven motors (to control oscillating pipes with nozzles), nozzles, spray boxes, and a computer-controlled operating system. Submersible pumps provide water from the underground storage tank below the laboratory to the rooftop storage tank. Water from the rooftop storage tank is supplied to each nozzle of the RS through the water delivery system. The booster pumps control the inflow of water from the rooftop storage tank to the water supply system, keeping the pressure constant and ensuring each nozzle has the similar (or the same) discharge rate. Through a drainage system on the ground, the raindrops released by nozzles are re-collected in the underground storage tank for reuse. Figure 1 shows the inside view of the NDMI RS laboratory and a schematic diagram of the water circulation process in the NDMI RS.
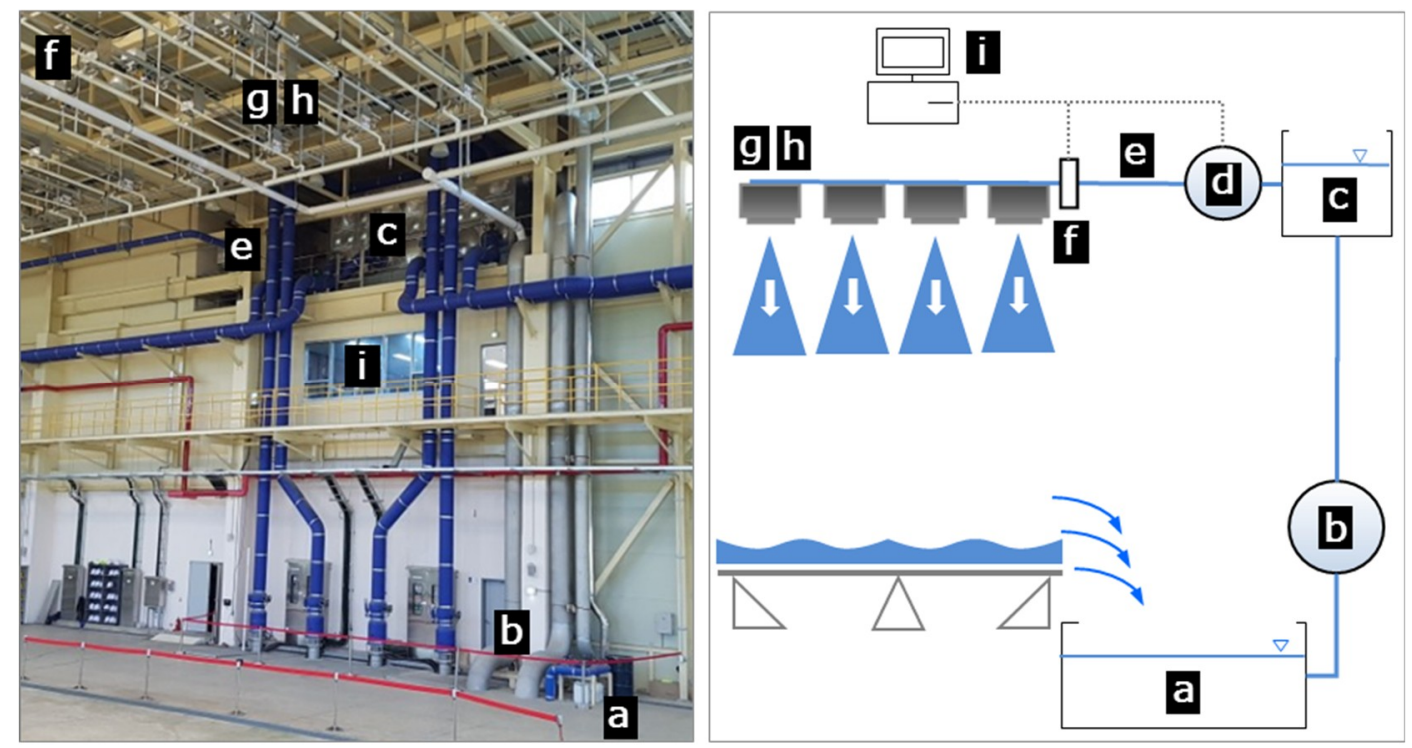

Figure 1. General view (left) and schematic diagram (right) of the National Disaster Management Research Institute Rainfall Simulator (NDMI RS): (a) underground water storage tank, (b) submersible pumps, (c) rooftop water storage tank, (d) booster pumps, (e) water supply system, (f) computer-driven motors, (g) nozzles, (h) spray boxes and (i) computer-controlled operating system.

The size of the RS is $30 \mathrm{~m}$ (length) by $30 \mathrm{~m}$ (width). The simulator and its experimental area can be divided into nine different sub-sections $(10 \times 10 \mathrm{~m})$ that can be operated independently, which enables efficient experiments ranging from small-scale models to actual-size testing. The simulator's nozzles are at a height of $12 \mathrm{~m}$ above the ground to ensure the terminal speed of raindrops. Four sets of nozzles are installed and equally spaced at a $2.5-\mathrm{m}$ distance along the pipelines of the sub-section. Each set consists of two nozzles. The nozzle type is KJ 80150 (an orifice diameter of $7.5 \mathrm{~mm}$ with a flat fan spray type). The configuration of the nozzles is presented in Figure 2. 


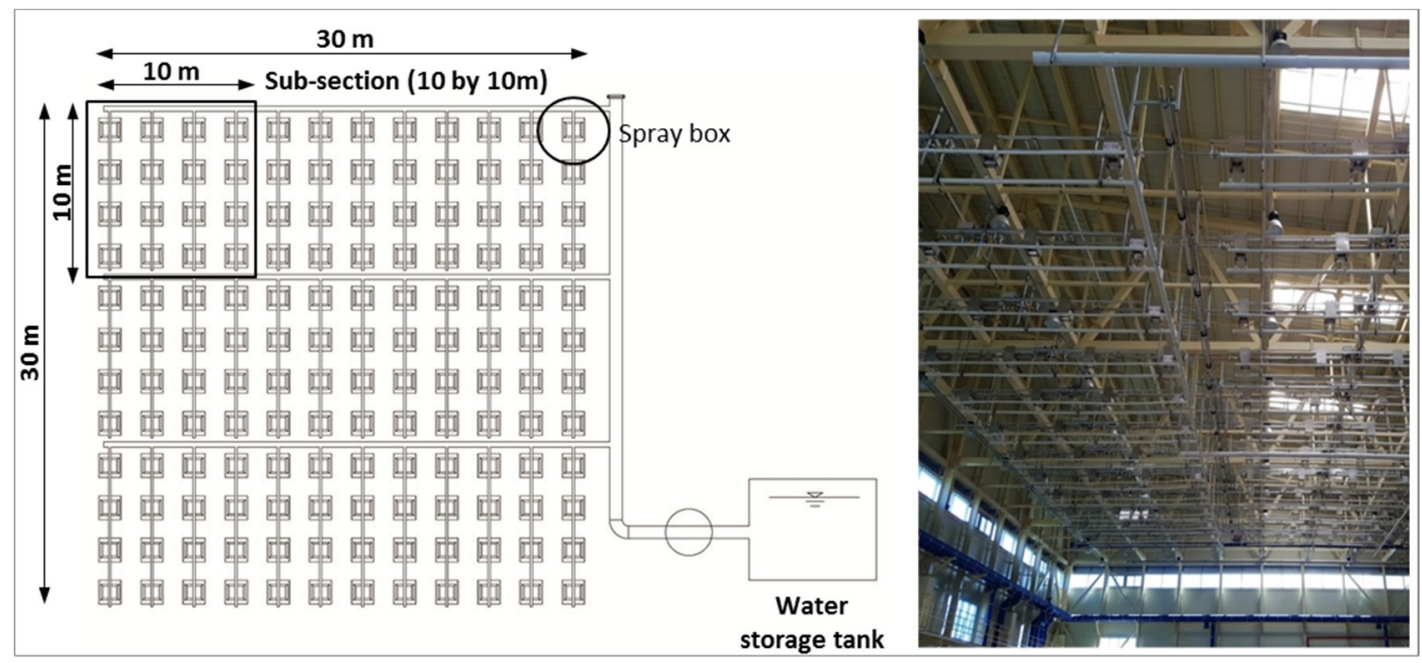

Figure 2. Nozzle configuration of the rainfall simulator.

The spray boxes beneath each pair of oscillating nozzles are used to reduce rainfall intensity by cutting off the spray. Details of the spray box structure are given in Figure 3. There are 144 spray boxes installed throughout the whole RS (see Figure 2). In general, the oscillating-nozzle system without spray boxes enables adjustment of simulated rainfall characteristics by changing the nozzle type used, the water pressure at the nozzle and the sweep oscillation frequency of the nozzles. In the case of the oscillating-nozzle system with spray boxes, the variables that control nozzle movement, which affects the intensity and uniformity of rainfall, are not only related to the velocity of oscillating nozzles across the spray box but also the time delay at the outside of the central square opening in the spray box. With nozzles located at the corner of the spray box, the water spray does not go through the central square hole of the spray box but is transferred through the gutter that transports water back to the underground storage tank.
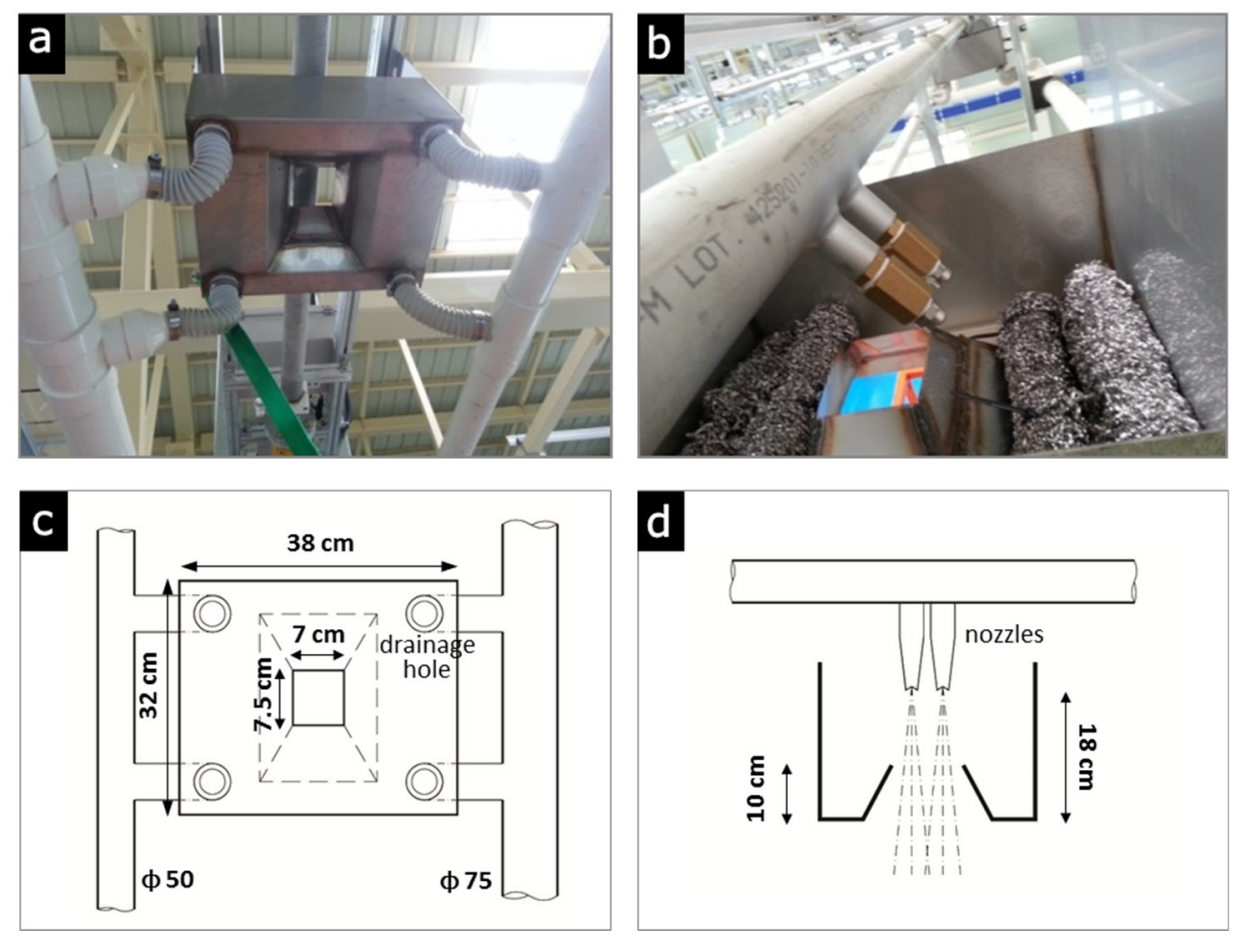

Figure 3. Spray box to reduce rainfall intensity in the rainfall simulator: (a) outside, (b) inside, (c) floor plan and (d) side view of the spray box. 
In the NDMI RS, the nozzle pressure (NP) ranges from 1.3 to $7.0 \mathrm{~kg} / \mathrm{cm}^{2}$ with an increment of 0.1 , yielding flow rates of 0.96 to $3.91 \mathrm{~m}^{3} / \mathrm{min}$. The oscillation velocity (OV) of nozzles varies from 6.25 to $31.25 \mathrm{rpm}$ with an increment of $1.25 \mathrm{rpm}$, and the time delay (TD) of nozzles in the spray boxes varies from 0 to $10 \mathrm{~s}$ with an increment of $0.1 \mathrm{~s}$. The system variables such as the NP, the OV, and the TD can be automatically changed using the computer-controlled operation system.

\section{Method}

\subsection{Development of an Automated Rainfall Collection System for a Large Laboratory Rainfall Simulator}

The ARCS was designed and constructed to automatically measure the repeatability and uniformity of storm events of the large laboratory RS. The size of the ARCS is $10 \mathrm{~m}$ (length) by $10 \mathrm{~m}$ (width). The ARCS can be operated based on 10 movable units (the size of each unit is $5 \mathrm{~m}$ (length) by $2 \mathrm{~m}$ (width)), which enable easy assembly and transport inside a laboratory. Figure 4 shows the design and components of the ARCS.
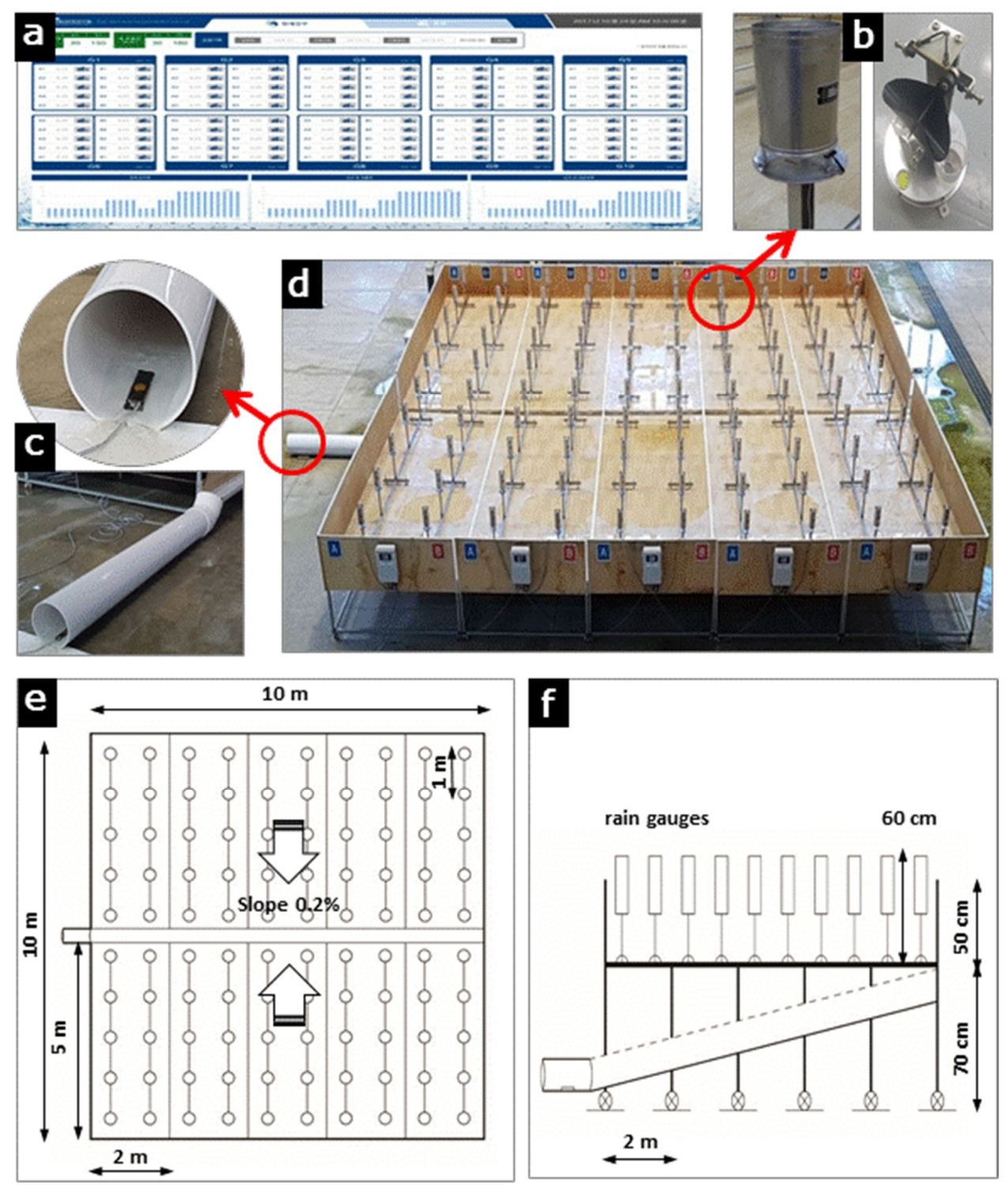

Figure 4. Design and components of the Automated Rainfall Collection System (ARCS): (a) real-time data processing system, (b) miniature tipping bucket rain gauges, (c) partially filled pipe ultrasonic flowmeter, (d) general view, (e) floor plan view, and (f) side view of the ARCS. 
The main components of the ARCS are miniature tipping bucket rain gauges, a partially filled pipe ultrasonic flowmeter, wireless data transmission devices, and a real-time data processing system. A miniature tipping bucket rain gauge $(10 \mathrm{~cm}$ in diameter with a $20-\mathrm{cm}$-high metal circular container, and resolution of 1 pulse per $0.25 \mathrm{~mm}$ ) was developed to efficiently cover a 1- by 1-m surface under the RS (Figure $4 \mathrm{~b}$ ). A total of 100 rain gauges were equally spaced over the entire ARCS plot in a grid pattern (Figure 4d,e) to measure the spatial rainfall distribution. The top of each rain gauge was located approximately $60 \mathrm{~cm}$ above the surface of the ARCS so that sprayed raindrops did not splash into the top of the collector (Figure $4 \mathrm{f}$ ).

The total rainfall intensity is determined by a partially filled pipe ultrasonic flowmeter installed at the end of the pipe (Figure 4c). Rainfall delivered by the RS is collected in the ARCS (Figure 4d) and the rain volume falling in the rain gauges is also collected in the ARCS at the same time. The rainfall falling in the rain gauges falls to a container ground of the ARCS through the holes below a tipping bucket (Figure $4 \mathrm{~b}$ ). The collected rainfall is transferred to a $250-\mathrm{mm}$ diameter PVC pipe below the ARCS (Figure 4f). The flowmeter measures the water level in the pipe every minute, and the total amount of rainfall collected from the ARCS is calculated as an equivalent intensity value of rainfall by accumulating the rainfall amount measured every minute. Data from the 100 rain gauges and the flowmeter are transmitted through wireless data transmission devices. The data are stored, processed and displayed in the real-time data processing system (Figure 4a).

\subsection{Evaluation of the Performance of the Rainfall Simulator}

The developed ARCS was implemented to calibrate the RS with respect to rainfall intensity and spatial uniformity. The rainfall intensity and the uniformity of the spatial rainfall distribution were evaluated on a plot size of $10 \mathrm{~m}$ (length) by $10 \mathrm{~m}$ (width) in the RS under 75 combinations of the three system variables (i.e., NP values of 1.3, 1.4 and $1.5 \mathrm{~kg} / \mathrm{cm}^{2}$; OV values of $6.25,12.50,18.75,25.00$, and $31.25 \mathrm{rpm}$; TD values of 0.0, 0.5, 1.0, 1.5 and $2.0 \mathrm{~s})$. The maximum value of NP was maintained at $1.5 \mathrm{~kg} / \mathrm{cm}^{2}$ to avoid overflow of excess water from the spray boxes when the NP exceeded $1.5 \mathrm{~kg} / \mathrm{cm}^{2}$. The TD increased from $0.5 \mathrm{~s}$ to $2.0 \mathrm{~s}$, with consideration of the physical characteristics of natural rainfall in no-rainfall intervals.

The rainfall intensity was measured by two different methods. In the first method, each rainfall intensity over the entire plot $(10 \mathrm{~m} \times 10 \mathrm{~m})$ was measured by 100 miniature tipping bucket rain gauges equally distributed in a square grid ( $1 \mathrm{~m}$ distance apart from each other). The average rainfall intensity $\left(\mathrm{I}_{\text {average }}\right)$ was then determined by averaging the 100 rainfall intensity measurements from the rain gauges. A volumetric method was adopted in the second approach. The total amount of rainfall collected in a container with a $100-\mathrm{m}^{2}$ capacity in the ARCS was measured by the partially filled pipe ultrasonic flowmeter. The volume of water collected in the ARCS was converted to an equivalent intensity value of rainfall (total rainfall intensity, $\mathrm{I}_{\text {total }}$ ). The accuracy of the average rainfall intensity ( $\mathrm{I}_{\text {average, }}$, measurement error of a tipping bucket rain gauge: $\pm 5 \%$ ) based on the rain gauges was evaluated through comparison with the total rainfall intensity $\left(\mathrm{I}_{\text {total }}\right.$, measurement error of a flowmeter: $\pm 2 \%$ ) measured using the flowmeter [36].

The uniformity of the simulated rainfall was evaluated using the Christiansen uniformity coefficient $(\mathrm{CuC})$ [35], which is the most widely used measure of spatial homogeneity in a certain rainfall event. The $\mathrm{CuC}$ is calculated from the formula

$$
\mathrm{CuC}=\left(1-\frac{\sum_{i=1}^{n}\left|x_{i}-\bar{x}\right|}{n \bar{x}}\right) \times 100(\%)
$$

where $x_{i}$ is the rainfall amount at location $i, \bar{x}$ is the mean amount of rainfall and $n$ is the total number of observations. The $\mathrm{CuC}$ is the deviation from the mean that is normalized by the average rainfall intensity of the respective observation points to characterise the spatial rainfall variability. The closer the value is to $100 \%$, the more uniform the spatial distribution of rainfall. A spatial pattern of rainfall can be considered as reasonably uniform over an experimental plot when the $\mathrm{CuC}$ is higher than 
$80 \%[37,38]$. However, there is a trade-off between uniformity and other objectives such as size and cost. In general, smaller RSs have higher $\mathrm{CuC}$ values [10]. For large experimental plots, a $\mathrm{CuC}$ value of $70 \%$ is considered reasonably acceptable [39].

The variability (or consistency) of the rainfall intensity and the spatial uniformity was investigated to assess the reliability and accuracy of the RS. Operation models of the RS were created in the condition of system variables showing a high degree of accuracy associated with the spatial uniformity in order to reproduce desirable rainfall intensities with a reasonably high uniformity distribution. The correlations between the system variables and the intensity and uniformity distribution of rainfall were investigated to identify possible interdependencies. The correlation between variables was tested by calculating a linear correlation coefficient. Additionally, correlation coefficients in log-transformed space were examined whether non-linear relationships exited between them. Correlation analysis with consideration of a significance level was performed to identify the degree of dependency for variables (i.e., the system variables of the RS and the simulated rainfall intensity and uniformity distribution). The functional relationships between the system variables of the RS and the simulated intensity and uniformity distribution of rainfall were established based on a multiple regression approach on linear and logarithm scales. The coefficient of determination was used to measure the performance of the operation models. The operation model with the highest coefficient of determination was then selected through the comparison of models on each scale.

\section{Results}

The RS has been calibrated for the rainfall intensity and the uniformity of rainfall distribution at various combinations of the system variables: the operating pressures and the oscillatory movements including velocity and time delay. Before assessing the reliability and accuracy of the RS based on calibration results, the adequacy of the average rainfall intensities $\left(I_{\text {average }}\right)$ from rain gauges for all system variables was evaluated through a graphical comparison with those measured by the flowmeter $\left(\mathrm{I}_{\text {total }}\right)$. As shown in Figure 5, the interaction points between $\mathrm{I}_{\text {average }}$ and $\mathrm{I}_{\text {total }}$ were evenly distributed on both sides of the 1:1 line in the relatively high rainfall range from 130 to $200 \mathrm{~mm} / \mathrm{h}$, while $\mathrm{I}_{\text {average }}$ was slightly overestimated for the rainfall range from 60 to $130 \mathrm{~mm} / \mathrm{h}$. However, the average rainfall intensities generally showed good agreement with the total rainfall intensities measured by the flowmeter. The fitted line between the values from $\mathrm{I}_{\text {average }}$ and $\mathrm{I}_{\text {total }}$ was very close to the 1:1 correspondence. The performance statistic also shows that $\mathrm{I}_{\text {average }}$ exhibited high accuracy in estimating rainfall intensities (an $R^{2}$ of 0.97 between the $\mathrm{I}_{\text {average }}$ and $\mathrm{I}_{\text {total }}$ values).

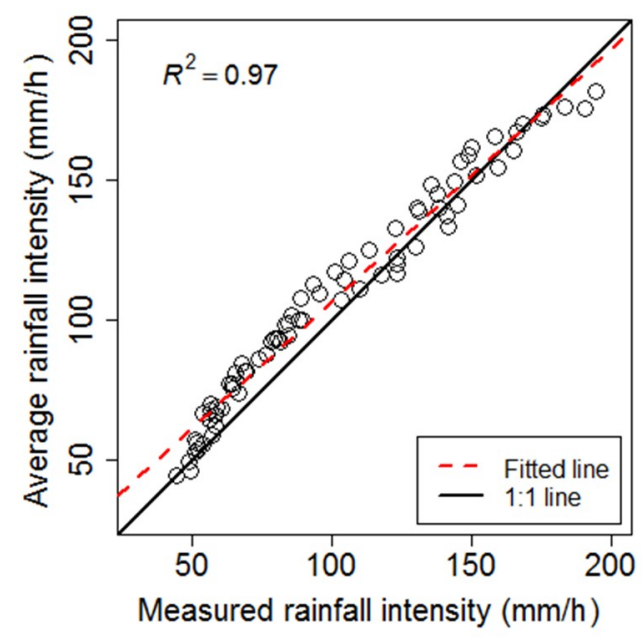

Figure 5. Comparison of the total rainfall intensity $\left(\mathrm{I}_{\text {total }}\right)$ measured by the flowmeter and the average rainfall intensity ( $\mathrm{I}_{\text {average }}$ ) measured using rain gauges ( $R^{2}$ represents the coefficient of determination). 
Sousa Junior et al. [36] estimated the average rainfall intensities using two different methods. One was the traditional manual measurement ( 63 collection cans arranged in a $7 \times 9$ mesh spaced $0.25 \mathrm{~m}$ apart in a $3-\mathrm{m}^{2}$ area). The other was a volumetric method in which the total amount of rainfall collected in a container $\left(3 \mathrm{~m}^{2}\right)$ was measured. These authors compared the rainfall intensities from two methods for rainfall ranging from 170 to $250 \mathrm{~mm} / \mathrm{h}$. The average rainfall intensities calculated from the traditional measurement were generally overestimated. There was a large difference in average rainfall intensities ranging from 170 to $200 \mathrm{~mm} / \mathrm{h}$ (the deviation between the values from the two methods was approximately $30 \sim 35 \mathrm{~mm} / \mathrm{h}$ ), while in this study, the difference between $\mathrm{I}_{\text {average }}$ and $\mathrm{I}_{\text {total }}$ was approximately $2 \sim 7 \mathrm{~mm} / \mathrm{h}$ for the same rainfall range.

The variability of the average rainfall intensity (hereinafter rainfall intensity) in response to the three system variables (i.e., based on 75 combinations of NP, OV, and TD) is compared in Table 1 and Figure 6. Table 1 provides a summary of statistics of the calibration results for the rainfall intensity for each system variable, and the variability in the rainfall intensity for each system variable is visually compared using box-and-whisker diagrams in Figure 6. The RS provided rainfall intensities between 44.1 and $181.7 \mathrm{~mm} / \mathrm{h}$ for the three system variables (Figure 6). As shown in Figure 6, a similar range of rainfall intensity was produced across all of the operating pressures (NP values of 1.3, 1.4 and $1.5 \mathrm{~kg} / \mathrm{cm}^{2}$ ). The average rainfall intensity increased slightly with increasing NP (an average of 104.5, 108.4 and $112.1 \mathrm{~mm} / \mathrm{h}$ in response to NP values of $1.3,1.4$ and $1.5 \mathrm{~kg} / \mathrm{cm}^{2}$, respectively; Table 1), but no substantial difference was detected with an increase in the NP value. By contrast, increases in the OV and TD values significantly decreased the rainfall intensity (the mean ranged from 82.6 to $140.5 \mathrm{~mm} / \mathrm{h}$ and from 72.8 to $162.6 \mathrm{~mm} / \mathrm{h}$ in response to OV and TD, respectively; Table 1). The lower the OV and TD, the higher the rainfall intensity of the RS.

Table 1. Statistics of the calibration results for the rainfall intensity in response to each system variable. NP: nozzle pressure; OV: oscillation velocity; TD: time delay

\begin{tabular}{|c|c|c|c|c|c|c|c|c|c|c|c|c|c|}
\hline \multirow{2}{*}{$\begin{array}{c}\text { Unit } \\
(\mathrm{mm} / \mathrm{h})\end{array}$} & \multicolumn{3}{|c|}{$\mathrm{NP}\left(\mathrm{kg} / \mathrm{cm}^{2}\right)$} & \multicolumn{5}{|c|}{ OV (rpm) } & \multicolumn{5}{|c|}{ TD (s) } \\
\hline & 1.3 & 1.4 & 1.5 & 6.25 & 12.5 & 18.75 & 25.0 & 31.25 & 0.0 & 0.5 & 1.0 & 1.5 & 2.0 \\
\hline Mean & 104.5 & 108.4 & 112.1 & 140.5 & 120.9 & 104.9 & 92.8 & 82.6 & 162.6 & 123.2 & 99.3 & 83.8 & 72.8 \\
\hline Median & 101.6 & 107.5 & 112.8 & 137.1 & 114.4 & 93.2 & 81.1 & 70.1 & 165.5 & 120.7 & 93.2 & 77.3 & 66.2 \\
\hline SD & 38.2 & 39.2 & 40.0 & 24.3 & 32.1 & 36.4 & 37.3 & 36.5 & 12.7 & 22.2 & 24.7 & 24.8 & 24.1 \\
\hline
\end{tabular}
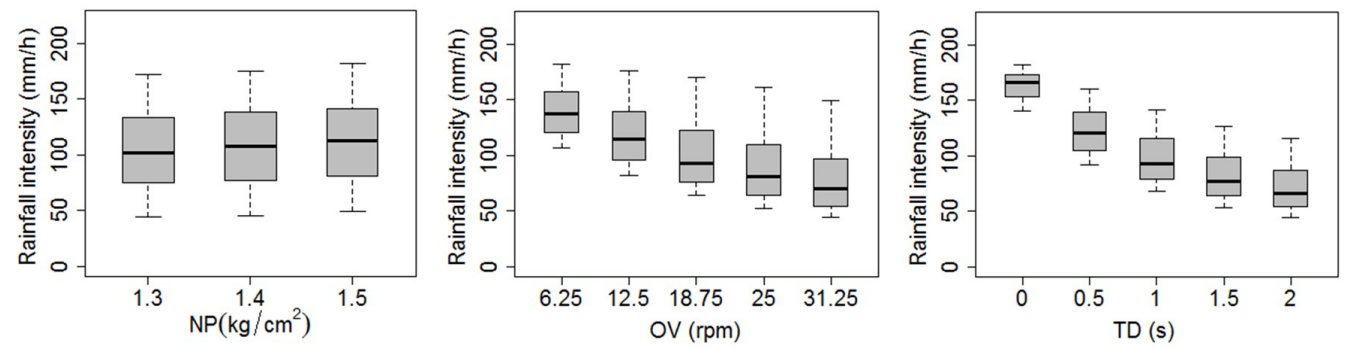

Figure 6. Variability in rainfall intensity for the three system variables (nozzle pressure (NP), oscillation velocity (OV) and time delay (TD)).

A summary of statistics of the calibration results for the spatial rainfall uniformity is shown in Table 2, and Figure 7 presents the range of the $\mathrm{CuC}$ values calculated in response to changes in the three system variables. The uniformity coefficient for all cases ranged between $70.1 \%$ (for NP of $1.3 \mathrm{~kg} / \mathrm{cm}^{2}$, OV of $31.25 \mathrm{rpm}$ and TD of $2.0 \mathrm{~s}$, which resulted in a rainfall intensity of $44.1 \mathrm{~mm} / \mathrm{h}$ ) and $78.4 \%$ (for NP of $1.5 \mathrm{~kg} / \mathrm{cm}^{2}$, OV of $6.25 \mathrm{rpm}$ and TD of $0.0 \mathrm{~s}$, which resulted in a rainfall intensity of $181.7 \mathrm{~mm} / \mathrm{h}$ ). The uniformity coefficient was influenced primarily by the change in NP and OV. The $\mathrm{CuC}$ values of simulated rainfall improved with an increase in NP, and the RS yielded higher values of uniformity coefficients at an NP value of $1.5 \mathrm{~kg} / \mathrm{cm}^{2}$ (CuC values ranged from 74.2 to $78.4 \%$ in Figure 7, with rainfall intensities ranging from 49.1 to $181.7 \mathrm{~mm} / \mathrm{h}$ in Figure 6). The spatial 
distributions of the simulated rainfall appeared to be improved with a decrease in OV. An increase in OV was inversely proportional to both the rainfall intensity and the uniformity coefficient (Figures 6 and 7), whereas the uniformity coefficient was not significantly affected by changes in TD. A sample plot for the spatial rainfall distribution (rainfall intensity of $181.7 \mathrm{~mm} / \mathrm{h}$ and $\mathrm{CuC}$ of $78.4 \%$ ) is presented in Figure 8. The overall spatial pattern of distributions for other rainfall intensities was broadly similar in terms of zones of high and low rainfall amounts despite the changing rainfall intensities.

Table 2. Statistics of the calibration results for the $\mathrm{CuC}$ (Christiansen uniformity coefficient) for each system variable.

\begin{tabular}{|c|c|c|c|c|c|c|c|c|c|c|c|c|c|}
\hline \multirow{2}{*}{ Unit (\%) } & \multicolumn{3}{|c|}{$\mathrm{NP}\left(\mathrm{kg} / \mathrm{cm}^{2}\right)$} & \multicolumn{5}{|c|}{ OV (rpm) } & \multicolumn{5}{|c|}{ TD (s) } \\
\hline & 1.3 & 1.4 & 1.5 & 6.25 & 12.5 & 18.75 & 25.0 & 31.25 & 0.0 & 0.5 & 1.0 & 1.5 & 2.0 \\
\hline Mean & 74.1 & 75.1 & 75.9 & 76.6 & 76.5 & 75.2 & 73.8 & 73.1 & 75.3 & 75.6 & 75.2 & 74.7 & 74.4 \\
\hline Median & 74.7 & 74.9 & 75.6 & 76.8 & 76.7 & 75.2 & 74.0 & 72.4 & 75.4 & 75.8 & 75.6 & 75.1 & 74.7 \\
\hline SD & 1.9 & 1.8 & 1.3 & 1.3 & 0.7 & 0.8 & 1.5 & 1.4 & 1.7 & 1.6 & 1.9 & 1.8 & 2.0 \\
\hline
\end{tabular}
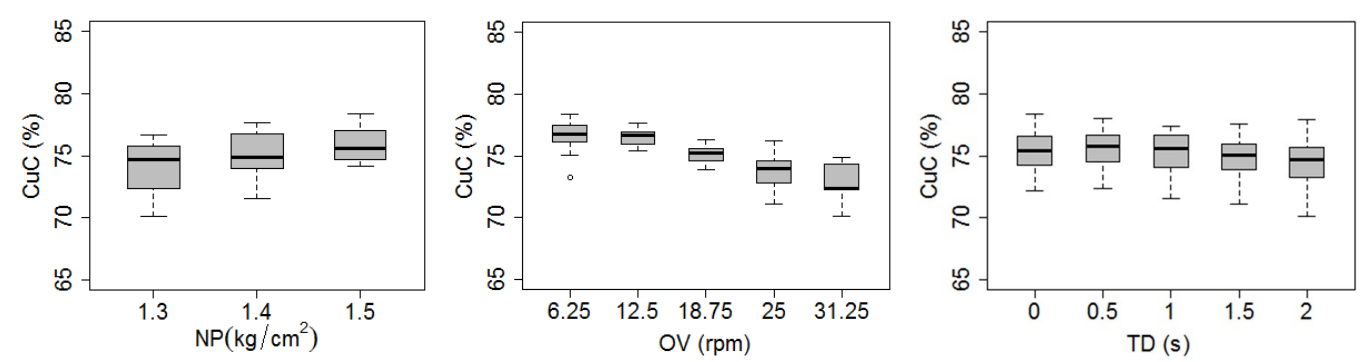

Figure 7. Variability in the Christiansen uniformity coefficient $(\mathrm{CuC})$ values in response to the three system variables (NP, OV and TD).

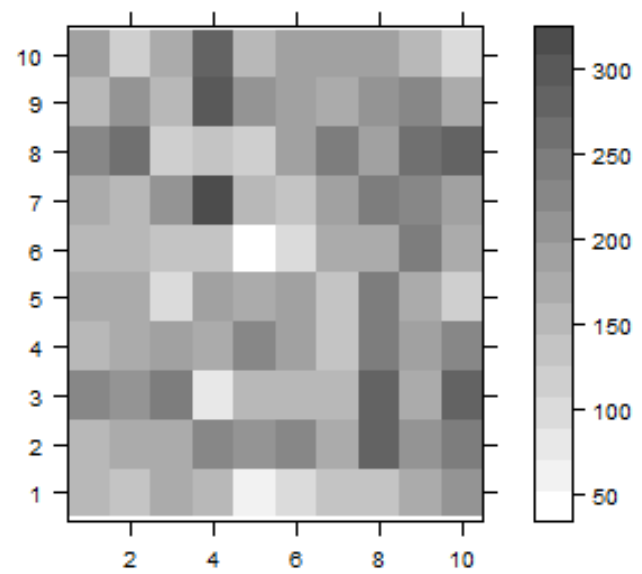

Figure 8. Spatial distribution of a rainfall intensity of $181 \mathrm{~mm} /$ h over the $10 \times 10 \mathrm{~m}$ plot surface $(\mathrm{CuC}$ of $78.4 \%)$.

The calibration results for the rainfall intensity and the spatial rainfall uniformity in response to each system variable revealed that OV had a strong relationship with both the rainfall intensity and the uniformity coefficient at the same time. Higher uniformity was also observed in response to an NP of $1.5 \mathrm{~kg} / \mathrm{cm}^{2}$, which included the whole range of rainfall intensities yielded from all combinations of the RS's system variables (NP, OV, and TD). In this study, the operation models of the RS were derived under the pressure condition (NP of $1.5 \mathrm{~kg} / \mathrm{cm}^{2}$ ) that had the highest level of spatial rainfall uniformity and included the range of rainfall intensities for all combinations of the three system variables, according to interrelationships between the system variables in the RS and the intensity and uniformity distribution of rainfall. 
Figure 9 represents scatter plots of the OV for each TD (i.e., 0.0, 0.5, 1.0, 1.5, and $2.0 \mathrm{~s}$ ) against the intensity and uniformity distribution of rainfall under the nozzle pressure condition of $1.5 \mathrm{~kg} / \mathrm{cm}^{2}$. Table 3 shows the correlations on linear and log-log scales between the OV for each TD and the intensity and uniformity distribution of rainfall. As represented in Figure 9, when the relationships between the intensity and uniformity distribution of rainfall and the OV were classified into five TDs, the closer the OV approached zero, the higher the intensity of simulated rainfall. The uniformity of rainfall distribution was slightly improved under conditions where the intensity of rainfall increased. However, as TD decreased, the rainfall intensity increased, while the change in TD did not significantly affect the change in the value of $\mathrm{CuC}$. Under all TD values, $\mathrm{OV}$ exhibited a strong negative correlation with both the rainfall intensity and the spatial uniformity of rainfall distribution (Table 3). In particular, correlations were significant at the $1 \%$ and $5 \%$ levels on linear and $\log$-log transformed scales.
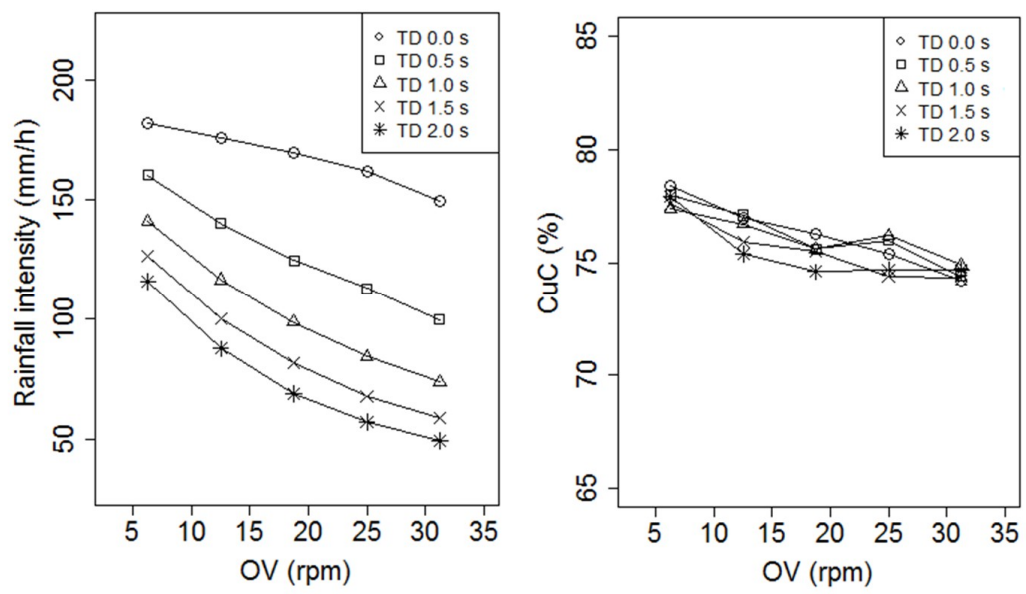

Figure 9. Scatter plots for the system variables in the RS (OV and TD) and the intensity and uniformity distribution of rainfall at an NP of $1.5 \mathrm{~kg} / \mathrm{cm}^{2}$.

Table 3. Correlation coefficients between the OV for each TD and the intensity and uniformity distribution of rainfall on linear and log-log transformed scales.

\begin{tabular}{ccccc}
\hline \multirow{2}{*}{ System Variable } & \multicolumn{2}{c}{ Normal Scale } & \multicolumn{2}{c}{ Log-Log Scale } \\
\cline { 2 - 5 } & Rainfall Intensity & CuC & Rainfall Intensity & CuC \\
\hline TD $(0.0 \mathrm{~s})$ & $-0.99^{* *}$ & $-0.99^{* *}$ & $-0.93^{*}$ & $-0.98^{* *}$ \\
TD $(0.5 \mathrm{~s})$ & $-0.99^{* *}$ & $-0.95^{* *}$ & $-0.98^{* *}$ & $-0.94^{*}$ \\
TD $(1.0 \mathrm{~s})$ & $-0.99^{* *}$ & $-0.90^{*}$ & $-0.99^{* *}$ & $-0.90^{*}$ \\
TD $(1.5 \mathrm{~s})$ & $-0.98^{* *}$ & $-0.95^{* *}$ & $-0.99^{* *}$ & $-0.92^{* *}$ \\
TD $(2.0 \mathrm{~s})$ & $-0.97^{* *}$ & $-0.80^{*}$ & $-1.00^{* *}$ & $-0.91^{*}$ \\
\hline
\end{tabular}

* Significant at the $5 \%$ level; ${ }^{* *}$ Significant at the $1 \%$ level.

The linear and non-linear operation models were derived using multiple regression to establish appropriate functional relationships between the system variables of the RS and the simulated intensity and uniformity distribution of rainfall with statistical significance. The performance of the operation models on linear and log-log scales was measured based on the coefficient of determination. The linear models yielded a higher model performance in both the rainfall intensity $\left(R^{2}\right.$ of 0.93 and 0.83 on linear and log-log scales, respectively) and the spatial uniformity coefficient $\left(R^{2}\right.$ of 0.84 and 0.82 on linear and log-log scales, respectively). The operation models with the corresponding coefficients of determination are presented in Table 4 . The operation models exhibited good overall performance with both the rainfall intensity and the uniformity coefficients $\left(R^{2}\right.$ value higher than 0.8$)$. In particular, the performance of the operation model for the rainfall intensity was better than that of the uniformity coefficient. 
Table 4. Operation models of the RS, derived from the functional relationships between the system variables of the RS and the simulated intensity and uniformity distribution of rainfall.

\begin{tabular}{ccc}
\hline & Operation Model & Coefficient of Determination $\left(\boldsymbol{R}^{2}\right)$ \\
\hline Rainfall intensity (I) & $200.474-2.317 \mathrm{OV}-44.932 \mathrm{TD}$ & 0.93 \\
Uniformity $(\mathrm{CuC})$ & $78.724-0.125 \mathrm{OV}-0.456 \mathrm{TD}$ & 0.84 \\
\hline
\end{tabular}

The variability of simulated rainfall intensity and its uniformity of distribution affected by the system variables (OV and TD) in the developed operation models are visually compared in Figure 10 based on certain values of the intensity and uniformity coefficient of rainfall (rainfall intensities of 50, 90, 130 and $170 \mathrm{~mm} / \mathrm{h}$ and $\mathrm{CuCs}$ of 75, 76, 77 and 78). The rainfall intensity increased with a decrease in both OV and TD. The uniformity coefficient improved with a decrease in OV, while the variation in TD did not have a significant effect on the $\mathrm{CuC}$ values (i.e., $\mathrm{CuC}$ values of 75,76 , and $77 \%$ were obtained across the whole range of TD from 0 to 2 s; Figure 10).

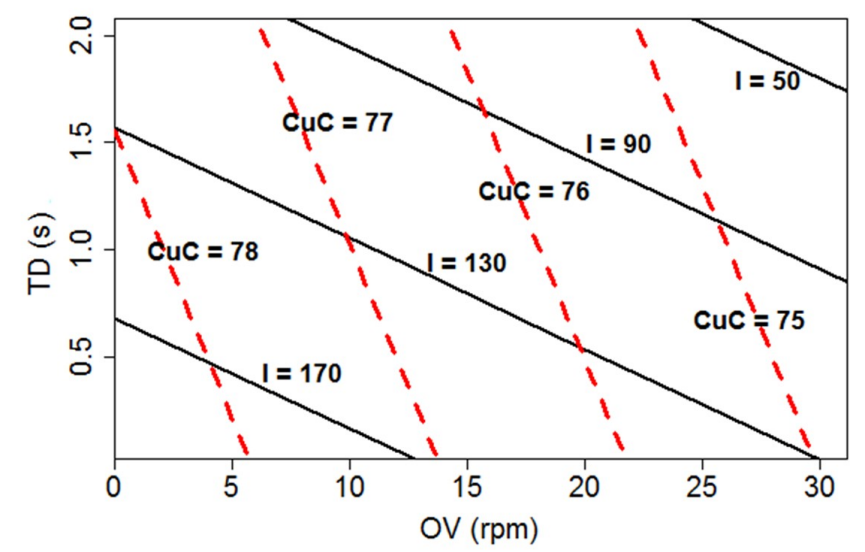

Figure 10. Variation in rainfall intensity (I) and uniformity coefficient $(\mathrm{CuC})$ in response to the system variables of the RS (OV and TD).

\section{Conclusions and Discussion}

An automated rainfall collection system (ARCS) was developed to overcome the disadvantages of manual measurement for obtaining the rainfall intensity and the spatial rainfall distribution in a large experimental area. The developed ARCS was implemented to calibrate a large-scale laboratory rainfall simulator for the rainfall intensity and spatial rainfall uniformity at various combinations of the system variables, such as the operating pressure (NP) and oscillatory movements, including velocity and time delay (OV and TD, respectively). Finally, operation models for the RS were derived from the functional relationships between the RS's system variables and the intensity and uniformity distribution of rainfall.

Prior to evaluating the reliability and accuracy of the RS, the adequacy of average rainfall intensities automatically collected from miniature tipping bucket rain gauges was assessed by comparison with those based on a volumetric method using a flowmeter. The comparative assessment of the estimation methods for the rainfall amount suggests that the average rainfall intensities automatically collected from the miniature tipping bucket rain gauges generally provided accurate and consistent predictions for both high and low ranges of rainfall from 40 to $200 \mathrm{~mm} / \mathrm{h}$. In particular, the automatic method in this study had a higher estimation accuracy for rainfall intensities than the traditional manual method when compared with the results reported by Sousa Junior et al. [36]. Therefore, careful consideration of the uncertainty issue when observing average rainfall intensity using the traditional manual method is needed when results from the traditional manual method are applied in hydrogeomorphological studies, such as surface property changes from 
fire, agriculture, urbanization, or other disturbance of the hydrologic cycle without comparison to the real rainfall intensity.

Calibration results showed that the simulated rainfall intensity and the uniformity of rainfall distribution were affected by the system variables of the RS (i.e., a pressurized oscillating nozzle simulator with spray boxes). The rainfall intensity was inversely proportional to increases in OV and $\mathrm{TD}$, while there was no substantial difference in the rainfall intensity with increasing NP, and the rainfall intensities were evenly distributed within the maximum and minimum values of rainfall at each NP value $\left(1.3,1.4\right.$ and $\left.1.5 \mathrm{~kg} / \mathrm{cm}^{2}\right)$. This indicates that the rainfall intensity varied more sensitively to changes in the system variables associated with the oscillatory movement of nozzles compared with the pump pressure. In general, rainfall intensities of a pressurized nozzle simulator are controlled by nozzle type, the orifice diameter of the nozzle and the pump pressure at the nozzle. The nozzle pressure predominantly affects rainfall intensities under the same condition such as nozzle type and nozzle orifice diameter.

The uniformity of rainfall distribution improved with decreasing OV and increasing NP. The improvement of the uniformity coefficient in response to a decrease in OV is related to an increase of the exposure time of the oscillating nozzle to the experimental plot surface. This indicates that the slower the OV (i.e., the exposure time of nozzle increases), the more the amount of rainfall increases, resulting in an increase in the uniformity coefficient. This is because the increased amount of simulated rainfall contributes to the even distribution of rainfall over the experimental plot affected by nozzle oscillation. Increasing the NP also increased the uniformity of rainfall distribution. It appears that rain drops are sprayed more evenly as the pump pressure at a nozzle increases. In addition, the range of $\mathrm{CuC}$ values was high (CuCs ranged from 74.2 to $78.4 \%$ in Figure 7 ) and the variation of $\mathrm{CuC}$ values was small (SD of 1.3 in Table 2) at the pump pressure of $1.5 \mathrm{~kg} / \mathrm{cm}^{2}$, but the range of $\mathrm{CuC}$ values was relatively low $(\mathrm{CuCs}$ ranged from 70.1 to $76.7 \%$ and from 71.6 to $77.7 \%$ at NP values of 1.3 and $1.4 \mathrm{~kg} / \mathrm{cm}^{2}$, respectively; Figure 7) and the variability of $\mathrm{CuC}$ values was large (SDs of 1.9 and 1.8 at respective NP values of 1.3 and $1.4 \mathrm{~kg} / \mathrm{cm}^{2}$; Table 2) below the pressure condition of $1.5 \mathrm{~kg} / \mathrm{cm}^{2}$. Considering these conditions, it seems appropriate to set the pressure condition of the RS to higher than $1.5 \mathrm{~kg} / \mathrm{cm}^{2}$ to ensure a high and consistent performance of the spatial distributions of simulated rainfall.

The operation models of the RS (i.e., functional relationships between the system variables of the RS and the simulated intensity and uniformity distribution of rainfall) were established at an NP of $1.5 \mathrm{~kg} / \mathrm{cm}^{2}$, which resulted in the highest level of spatial rainfall uniformity and included the whole range of rainfall intensities for all combination of the system variables simultaneously. The operation models were derived based on a multiple regression approach that incorporated correlation analysis on linear and logarithm scales, with consideration of a significance level. The operation models exhibited high accuracy for both the rainfall intensity and the uniformity coefficients $\left(R^{2}\right.$ value higher than 0.8 , see Table 4). The rainfall intensity and the uniformity coefficient increased with decreases in OV and TD. In particular, the variation of OV had a notable effect on both the simulated rainfall intensity and the uniformity distribution of rainfall, while the effect of TD changes on the $\mathrm{CuC}$ values was small.

The simulated rainfall intensities and the uniformity coefficients of rainfall for their respective values were plotted against OV and TD to provide a visual inspection of the variation of the intensity and uniformity distribution of rainfall influenced by the system variables. This information on a graphical plot can be used as a guideline for appropriate ranges of the system variables to generate a specific rainfall intensity and degree of uniformity for simulated rainfall. In addition, information is provided on intuitive selection criteria of the system variable ranges for producing a specific intensity and uniformity of rainfall for specific applications. However, further experiments using the ARCS for various types of nozzles and pump pressures are required to generalize the operation models of the RS for various rainfall conditions. In particular, to increase the limited pump pressure for a nozzle used in this study $\left(1.3 \sim 1.5 \mathrm{~kg} / \mathrm{cm}^{2}\right)$, it is necessary to improve the drainage capacity of the spray box to drain the overflowing water when the nozzle pressure exceeds $1.5 \mathrm{~kg} / \mathrm{cm}^{2}$. In order to further improve 
the spatial variability of the rainfall intensity, it is also necessary to measure the pressure drop along the water supply system (from booster pumps to nozzles) and the pressure variation at each nozzle. Furthermore, additional research on comparisons of manual and automatic methods based on various conditions such as container size, grid size and rainfall range is required to quantify the magnitude of rainfall errors resulting from the traditional manual method.

Author Contributions: Supervision, H.K.; project administration, H.K.; methodology, H.K.; writing: review and editing, T.K.; data curation, H.J.; visualization, S.Y.

Funding: This research received no external funding.

Acknowledgments: This paper is supported by 'National Disaster Management Research Institute'.

Conflicts of Interest: The authors declare no conflict of interest.

\section{References}

1. Pérez-Latorre, F.J.; Castro, L.; Delgado, A. A comparison of two variable intensity rainfall simulators for runoff studies. Soil Tillage Res. 2010, 107, 11-16. [CrossRef]

2. Aksoy, H.; Unal, N.E.; Cokgor, S.; Gedikli, A.; Yoon, J.; Koca, K.; Inci, S.B.; Eris, E. A rainfall simulator for laboratory-scale assessment of rainfall-runoff-sediment transport processes over a two-dimensional flume. CATENA 2012, 98, 63-72. [CrossRef]

3. Isidoro, J.M.G.P.; de Lima, J.L.M.P. Hydraulic system to ensure constant rainfall intensity (over time) when using nozzle rainfall simulators. Hydrol. Res. 2015, 46, 705. [CrossRef]

4. Lascelles, B.; Favis-Mortlock, D.T.; Parsons, A.J.; Guerra, A.J.T. Spatial and temporal variation in two rainfall simulators: Implications for spatially explicit rainfall simulation experiments. Earth Surf. Process. Landf. 2000, 25, 709-721. [CrossRef]

5. Iserloh, T.; Ries, J.B.; Arnáez, J.; Boix-Fayos, C.; Butzen, V.; Cerdà, A.; Echeverría, M.T.; Fernández-Gálvez, J.; Fister, W.; Geißler, C.; et al. European small portable rainfall simulators: A comparison of rainfall characteristics. CATENA 2013, 110, 100-112. [CrossRef]

6. Abudi, I.; Carmi, G.; Berliner, P. Rainfall simulator for field runoff studies. J. Hydrol. 2012, 454-455, 76-81. [CrossRef]

7. Lassu, T.; Seeger, M.; Peters, P.; Keesstra, S.D. The Wageningen rainfall simulator: Set-up and calibration of an indoor nozzle-type rainfall simulator for soil erosion studies. Land Degrad. Dev. 2015, 26, 604-612. [CrossRef]

8. Blanquies, J.; Scharff, M.; Hallock, B. The design and construction of a rainfall simulator. In Proceedings of the 34th Annual Conference and Expo., Las Vegas, NV, USA, 24-28 February 2003.

9. Esteves, M.; Planchon, O.; Lapetite, J.M.; Silvera, N.; Cadet, P. The 'EMIRE' large rainfall simulator: Design and field testing. Earth Surf. Process. Landf. 2000, 25, 681-690. [CrossRef]

10. Wilson, T.G.; Cortis, C.; Montaldo, N.; Albertson, J.D. Development and testing of a large, transportable rainfall simulator for plot-scale runoff and parameter estimation. Hydrol. Earth Syst. Sci. 2014, 18, 4169-4183. [CrossRef]

11. Pall, R.; Dickinson, W.T.; Reals, D.; McGirr, R. Development and calibration of a rainfall simulator. Can. Agric. Eng. 1983, 25, 181-187.

12. Cerdà, A.; Ibáñez, S.; Calvo, A. Design and operation of a small and portable rainfall simulator for rugged terrain. Soil Technol. 1997, 11, 163-170. [CrossRef]

13. Grierson, I.T.; Oades, J.M. A rainfall simulator for field studies of run-off and soil erosion. J. Agric. Eng. Res. 1977, 22, 37-44. [CrossRef]

14. Meyer, L.D.; Harmon, W.C. Multiple-intensity rainfall simulator for erosion research on row sideslopes. Trans. ASAE 1979, 22, 100. [CrossRef]

15. Miller, W.P. A solenoid-operated, variable intensity rainfall simulator. Soil Sci. Soc. Am. J. 1987, 51, 832-834. [CrossRef]

16. Bubenzer, G.D. Inventory of rainfall simulators. In Proceedings of the Rainfall Simulator Workship, Tucson, AZ, USA, 7-9 March 1979; pp. 120-131.

17. Clarke, M.A.; Walsh, R.P.D. A portable rainfall simulator for field assessment of splash and slopewash in remote locations. Earth Surf. Process. Landf. 2007, 32, 2052-2069. [CrossRef] 
18. Dye, P.J.; Croke, B.F.W. Evaluation of streamflow predictions by the IHACRES rainfall-runoff model in two South African catchments. Environ. Model. Softw. 2003, 18, 705-712. [CrossRef]

19. Lørup, J.K.; Refsgaard, J.C.; Mazvimavi, D. Assessing the effect of land use change on catchment runoff by combined use of statistical tests and hydrological modelling: Case studies from Zimbabwe. J. Hydrol. 1998, 205, 147-163. [CrossRef]

20. Letcher, R.A.; Schreider, S.Y.; Jakeman, A.J.; Neal, B.P.; Nathan, R.J. Methods for the analysis of trends in streamflow response due to changes in catchment condition. Environmetrics 2001, 12, 613-630. [CrossRef]

21. Wang, S.; Kang, S.; Zhang, L.; Li, F. Modelling hydrological response to different land-use and climate change scenarios in the Zamu River basin of northwest China. Hydrol. Process. 2008, 22, 2502-2510. [CrossRef]

22. Kim, H.S.; Croke, B.F.W.; Jakeman, A.J.; Chiew, F.H.S. An assessment of modelling capacity to identify the impacts of climate variability on catchment hydrology. Math. Comput. Simul. 2011, 81, 1419-1429. [CrossRef]

23. Genxu, W.; Guangsheng, L.; Chunjie, L. Effects of changes in alpine grassland vegetation cover on hillslope Hydrological Processes. in a permafrost watershed. J. Hydrol. 2012, 444, 22-33. [CrossRef]

24. Maetens, W.; Vanmaercke, M.; Poesen, J.; Jankauskas, B.; Jankauskiene, G.; Ionita, I. Effects of land use on annual runoff and soil loss in Europe and the Mediterranean: A meta-analysis of plot data. Prog. Phys. Geogr. Earth Environ. 2012, 36, 599-653. [CrossRef]

25. Paige, G.; Stone, J.J.; Smith, J.R.; Kennedy, J. The Walnut Gulch rainfall simulator: A computer-controlled variable intensity rainfall simulator. Appl. Eng. Agric. 2004, 20, 25-31. [CrossRef]

26. Parsons, A.J.; Stone, P.M. Effects of intra-storm variations in rainfall intensity on interrill runoff and erosion. CATENA 2006, 67, 68-78. [CrossRef]

27. Sepaskhah, A.R.; Shahabizad, V. Effects of water quality and PAM application rate on the control of soil erosion, water infiltration and runoff for different soil textures measured in a rainfall simulator. Biosyst. Eng. 2010, 106, 513-520. [CrossRef]

28. Tromp-van Meerveld, H.J.; Parlange, J.-Y.; Barry, D.A.; Tromp, M.F.; Sander, G.C.; Walter, M.T.; Parlange, M.B. Influence of sediment settling velocity on mechanistic soil erosion modeling. Water Resour. Res. 2008, 44. [CrossRef]

29. Borselli, L.; Torri, D.; Poesen, J.; Sanchis, P.S. Effects of water quality on infiltration, runoff and interrill erosion processes during simulated rainfall. Earth Surf. Process. Landf. 2001, 26, 329-342. [CrossRef]

30. de Lima, J.L.M.P.; Singh, V.P.; Isidoro, J.M.G.P.; de Lima, M.I.P. Incorporating the effect of moving storms into hillslope hydrology: Results from a multiple-slope soil flume. In Proceedings of the ASCE World Environmental and Water Resources Congress, Palm Springs, CA, USA, 22-26 May 2011; pp. 1398-1407.

31. Nolan, S.C.; van Vliet, L.J.P.; Goddard, T.W.; Flesch, T.K. Estimating storm erosion with a rainfall simulator. Can. J. Soil Sci. 1997, 77, 669-676. [CrossRef]

32. Arnaez, J.; Lasanta, T.; Ruiz-Flaño, P.; Ortigosa, L. Factors affecting runoff and erosion under simulated rainfall in Mediterranean vineyards. Soil Tillage Res. 2007, 93, 324-334. [CrossRef]

33. Humphry, J.B.; Daniel, T.C.; Edwards, D.R.; Sharpley, A.N. A portable rainfall simulator for plot-scale runoff studies. Appl. Eng. Agric. 2002, 18, 199-204. [CrossRef]

34. Gabrić, O.; Prodanović, D.; Plavšić, J. The effects of oscillating nozzle on Christiansen's uniformitiy coefficient. Tech. Gaz. 2015, 22, 1415-1418.

35. Christiansen, J.E. Irrigation by Sprinkling; California Agricultural Experiment Station Bulletin 670, University of California: Berkeley, CA, USA, 1942.

36. Sousa Júnior, S.F.; Mendes, T.A.; Siqueira, E.Q. Development and calibration of a rainfall simulator for hydrological studies. Braz. J. Water Resour. 2017, 22. [CrossRef]

37. Moazed, H.; Bavi, A.; Boroomand-Nasab, S.; Naseri, A.; Albaji, M. Effects of climatic and hydraulic parameters on water uniformity coefficient in solid set systems. J. Appl. Sci. 2010, 10, 1792-1796. [CrossRef]

38. Neff, E.L. Why rainfall simulation? In Proceedings of the Rainfall Simulator Workship, Tucson, AZ, USA, 7-9 March 1979; pp. 3-7.

39. Luk, S.H.; Abrahams, A.D.; Parsons, A.J. Sediment sources and sediment transport by rill flow and interrill flow on a semi-arid piedmont slope, Southern Arizona. CATENA 1993, 20, 93-111. [CrossRef]

(C) 2018 by the authors. Licensee MDPI, Basel, Switzerland. This article is an open access article distributed under the terms and conditions of the Creative Commons Attribution (CC BY) license (http:/ / creativecommons.org/licenses/by/4.0/). 